\title{
Goethe and the study of life: a comparison with Husserl and Simmel
}

\author{
Elke Weik ${ }^{1}$
}

Published online: 22 September 2016

(C) The Author(s) 2016. This article is published with open access at Springerlink.com

\begin{abstract}
In the paper at hand I introduce Goethe's ontology and methodology for the study of life as an alternative to current theories. 'Life,' in its individual, social and/or pan-natural form, has been a recurring topic in the social sciences for the last two centuries and may currently experience a renaissance, if we are to believe Scott Lash. Goethe's approach is of particular interest because he formulated it as one of the first critical responses to the nascent discipline of biology. It can be characterised broadly as phenomenology with a strong dose of life philosophy. For this reason, and to draw its contours more clearly, I compare his approach to the respective thoughts in Husserl's and Simmel's work. The comparison focuses on the two central concepts phenomenon and life but also discusses broader epistemological and methodological issues, such as the relationship between observer and observed, the relationship between culture (cultural sciences) and nature (natural sciences), the nature of causality as well as preferred methods of study.
\end{abstract}

Keywords Life - Goethe $\cdot$ Husserl $\cdot$ Simmel $\cdot$ Phenomenon - Delicate Empirics

The problem of the study of social life has been a recurring theme in sociology and organization theory. With the demise of structural functionalism and contingency theory in the late 1960s scholars felt a need to get closer to the more fleeting aspects of social life in groups, organisations and institutions. Despite their best intentions, however, the concept seems today as elusive as ever. Lloyd Sandelands has put it quite succinctly: 'The basic facts of human social life - that it is social and that it is alive - are easily overlooked' (Sandelands 1995: 147). While the dynamisation of institutionalist theory and organisation theory in the 1980s and a new interest in

Elke Weik

e.weik@le.ac.uk

1 University of Leicester, Leicester, UK 
process theory and philosophy starting in the 2000s (among others, Chia and King 1998; Clegg et al. 2005; Cooper 2007; Hernes 2008) have certainly helped modelling the fluidity of social life, the peculiar characteristics of 'life' as such have hardly been discussed alongside it. (The work of Sandelands being one of the exceptions). And while Lash (2005), arguing from a perspective of a sociology of (high/late/post-) modernity, would like to see a 'Lebenssoziologie' (re-)instated, he too needs effectively to go back a century to find the conceptual tools to discuss it.

It is hence the objective of this paper to explore a theory that might help us understand the phenomenon of life better. I am proposing the scientific part of the work of Johann Wolfgang von Goethe. I do this for two reasons. The first, almost a sine qua non, is that his study of life is well conceptualised and applicable today. The second is that Goethe lived at a moment of time when the study of life became 'scientized.' During Goethe's lifetime, Gottfried Treviranus coined the term 'biology' (Lenoir 1987), Alexander von Humboldt undertook his travels, Georges de Cuvier proposed that species could become extinct, Carl von Linné (Linnaeus) devised his taxonomy of plants and animals still used in Biology today, and Charles Darwin undertook his voyage on the 'Beagle.' Goethe either corresponded with each of them or, in the case of Darwin, was at least known and cited (Richards 2002). Only a generation after Goethe's death, however, the direction of the Natural Sciences changed towards a materialist-reductionist approach that, in retrospect, has impeded the study of life rather than promoted it. Goethe anticipated this move and opposed it without, however, being able to stop it. By going back to this crossroads we may be able to get a truly alternative view of the study of life, a 'science of qualities' that gives room to the material as well as the spiritual aspects of both the study of life and the study of life.

In contrast to some papers recently published (Bleicher 2007; Levine 2012), I will not look at Goethe from Simmel's perspective, which in some respects I do not share. Rather I will look at Goethe as an author in his own right and oeuvre. To sharpen the contours of his theory I will do a 'weighted comparison' in the sense that the two other authors will only serve as a foil to Goethe and not be presented in their own right.

Selecting the authors to contrast him with I have gone back to the turn of the last century because it is there when the two concepts most pertinent to his study-life and phenomenon-became academically defined in a manner that is still accepted today. This is not to say that there have not been definitions and accounts before that time but they have been mostly superseded by the two eponymous schools I am discussing, viz. Phenomenology and Life Philosophy (Lebensphilosophie). Talking about phenomenology I will mostly draw on the works of its founder, Edmund Husserl. While his philosophy has subsequently been imported into sociology by Alfred Schütz and Thomas Luckmann and has formed a distinct school there, this school has developed a strong interest in a sociology of knowledge that is not really pertinent to what I want to discuss in this paper. Life philosophy, on the other hand, has a prominent sociological author in the person of Georg Simmel. Both Simmel and the school as such, however, have had the misfortune to become rather marginalized after World War II. 
The caveat remains that I am comparing authors from different epochs, different disciplines and with different research objectives. It may be ameliorated by the fact that the study of life is a truly interdisciplinary concern and thus contributions from every discipline can be brought to bear on it. The comparison will focus on the two central concepts phenomenon and life but also discuss broader epistemological and methodological issues, such as the relationship between observer and observed, the relationship between culture (cultural sciences) and nature (natural sciences), the nature of causality, preferred methods of study as well as the role of ratiocination and formal-mathematical methods.

\section{The authors: a brief on dates, aims and contexts}

Johann Wolfgang von Goethe (1749-1832) was a contemporary of Kant, Hegel and Linné. While generally recognised as one of the greatest German poets, his scientific works (mostly in geology, biology and physics) have met with reserved praise. Many natural scientists over the centuries have criticised major parts of his empirical work. Great names like Einstein, Heisenberg, Helmholtz and Planck, however, have embraced his overall ambition to maintain a 'human dimension' in the natural sciences (Jensen 2011; Schad 1977) ${ }^{1}$ that was lost in the materialistreductive turn mentioned above. Goethe's scientific legacy lives on in anthroposophical circles (for example, Steiner Schools) but also on the margins of the traditional university disciplines (Holdrege 2005; Schad 1977), and most recently complexity theory (Goodwin 1997). ${ }^{2}$ In the best known parts of his scientific works Goethe takes on the giants of his time: Isaac Newton in his 'Theory of Colours' (Farbenlehre, 1810) as well as Carl von Linné (Linnaeus) in his 'Metamorphosis of Plants' (Metamorphose der Pflanzen, 1790). Although Goethe illustrates his ideas on the phenomenon in the former, it is the latter that is of more interest to us. Goethe, as I will discuss in more detail below, argues against Linnés taxonomy that the system does not take into consideration that its objects are alive and evolving.

Edmund Husserl (1859-1938) is the founder of Philosophical Phenomenology. His thoughts were later to be imported into sociology by, most prominently, Alfred Schütz and Thomas Luckmann. Like many authors of grand theories Husserl changed his views on certain aspects of his philosophy over the years, and we can see it move from a more formal argument in 'Logical Investigations' (Logische Untersuchungen, 1900/01) towards what might be called a more applied interest in the life-world and the sciences expressed in 'The Crisis of European Sciences and Transcendental Philosophy' (Die Krisis der europäischen Wissenschaften und die transzendentale Phänomenologie, 1936). Publishing in an academic community embedded in German Idealism and Marxism on the one hand and positivist science

\footnotetext{
1 According to Holton (Galison et al. 2008: 10), Goethe's works 'loomed largest' in Einstein's personal library.

${ }^{2}$ Goodwin claims to conduct his whole investigation in a 'Goethean spirit' holding that it is the originality of Goethe's science that keeps it marginalised (Goodwin 1997: 136).
} 
(especially Psychologism ${ }^{3}$ ) on the other, Husserl sought to establish a philosophy that could provide a foundation for the sciences-without drawing on them. He shared their desire for objectivity and an ultimate grounding of knowledge, but thought that what the natural sciences offered was only a 'Scientific Objectivism,' i.e. a concern for the objective truth of the world of experience. This 'Scientific Objectivism' lacked any understanding of the prerequisites for experiencing the world; prerequisites that were, according to Husserl, situated in a transcendental subjectivity. ${ }^{4}$ There he claimed to have found these undoubtable foundations, or 'the absolute given' (absolute Gegebenheit) as he called them, in the cogitatio (the thinking act) and its corresponding cogitatum (thought, content). They constitute what he calls a 'phenomenon.'

Georg Simmel (1858-1918) is a thinker that is today often classified as a sociologist but saw himself as a philosopher (Swedberg 2011). The study of life marked, according to his own testimony, his most important and enduring concern among a work that is astoundingly multi-faceted. It culminated in his last book 'The View of Life' (Lebensanschauung 1918). Simmel admired and drew heavily on Goethe, on whom he published several essays as well as a book. His fascination with the latter is often categorised as a critique of Kant's philosophy and the Newtonian view of natural science (for example, Bleicher 2007). Although the contrast between the two thinkers is the main subject of Simmel's book 'Kant und Goethe' (1916), Simmel's stance towards, and reception of, the two authors is probably more subtle than a simple juxtaposition condemning Kant and elevating Goethe (Levine 2012). Simmel's position within the life philosophy (Lebensphilosophie) movement is more on the margins than in the centre, which is occupied by authors like Schopenhauer, Nietzsche, Dilthey, Bergson and William James (Fellmann 1996).

\section{Central concepts}

\subsection{Life}

The basic characteristic of a living unit: to separate, to unite, to become universal, to remain particular, to change, to specify and to present itself and to vanish under a thousand conditions that the living may choose, to solidify and to melt, to freeze and to flow, to extend and to contract. As all these effects happen at the same time, everything and anything can happen. Becoming and perishing, creating and destroying, birth and death, joy and sorrow, everything mingles in the same sense and measure; this is why the most particular can always appear as representation and simile for the most universal. (Goethe 1998 b, no. 21, my translation)

\footnotetext{
${ }^{3}$ Psychologism (Psychologismus) maintains that all social and cultural phenomena as well as philosophy can be reduced to psychological phenomena.

${ }^{4}$ As opposed to a psychological conception of an individual's subjectivity, transcendental subjectivity relates to a general capacity of human consciousness to constitute the experience of the world (Husserl 1962: §14).
} 
This is how Goethe ${ }^{5}$ characterises life and living organisms. The immediate impression one gets is of constant movement and a strong interrelatedness. The first impression, constant movement, leads us to Goethe's primary objective for undertaking studies of nature, for his aim is to study nature and life as alive, i.e. as constantly developing. Never the one to produce static descriptions or dead classifications, Goethe seeks to understand the most basic characteristic of lifedevelopment or change-in adequate terms and with new methods. 'Morphogenesis' is Goethe's name for the development of a living being in accordance with its 'programme.' ${ }^{6}$ Organisms are subject to a formative drive (Bildungstrieb) that powers it. It is important to note that the German word 'Bildung' also refers to education and cultivation because this points to the spiritual ${ }^{7}$ dimension in the development of living organisms. In this sense, Bildung goes beyond Gestalt invoking both the formation process and its result. The Bildungstrieb is powered by a tension in the ontological polarity between spirit and matter. It is hence not a pure, unrestrained life force but an interplay of such a life force with fixed laws and structures. Goethe (1998a: 34) gives a brief list of the forces involved in this interplay as shown in Fig. 1. As a consequence life is always formed and unfolds in rhythms (Schad 1977).

True creativity in art as in nature, Goethe would hold, is a product not of unrestrained, shapeless productiveness but of an inner creative force that disciplines itself to adhere to certain forms of communication or other forms of production. The spiritual dimension of the Bildungstrieb, as Robbins (2006) argues, can be seen in the fact that life, even in the lowest organisms, evaluates its environment in terms of 'good/bad for me.' This evaluation cannot be explained in terms of a mechanistic, non-organic universe. For Goethe, its is the intensification of experience that leads from the material to the spiritual (Naydler 1996). The strong emphasis on the spiritual nature as well as the qualitative aspects of change leads Goethe to reject the quantitative-mathematical approach of the Natural Sciences (see below). He argues that living organisms cannot be measured and compared like mechanic artefacts. On the contrary, every evaluation needs to take into account this 'inner' measure, which is a spiritual, non-sensual measure.

\footnotetext{
5 Goethe has never compiled his thoughts on doing science in a systematic manner. Apart from the two books mentioned in the introduction, there exist a multitude of short pieces, letters and even poetry on the subject. The following authors have helped me find my way through this ocean of ideas: Bortoft (1986), Stephenson (1995), Naydler (1996) and Jensen (2011). Authors that have contributed more specific aspects will be mentioned in the respective places in the text.

6 I could not determine from Goethe's writings whether this 'programme' is of an individual or typical (i.e. species-related) nature. The logic of his Morphology would suggest a typical programme unfolding in each plant or animal. As such, Goethe has been understood as a precursor of Darwin. Darwin's species, however, are linked by a (nowadays) empirically detectable 'programme' displayed in the chromosomes. This 'programme' produces the genotype, which has phenotypical variations depending on individual life circumstances. Goethe's morphotype, in contrast, is an idea or principle of unity (Lenoir 1987; Naydler 1996). Unfortunately, he also speaks of Leibnizian monads in other passages, e.g.: '... Life, the movement of the monas around itself...' (Goethe 1998b, no. 227, my translation). This indicates an individual 'programme'.

7 The German word 'Geist' is often translated by 'spirit' although it should be noted that the distinctions between 'Geist/Seele' on the one hand and 'Mind/Spirit/Soul' on the other are drawn along different lines. 'Geist' has a firm component of 'mind' in it.
} 


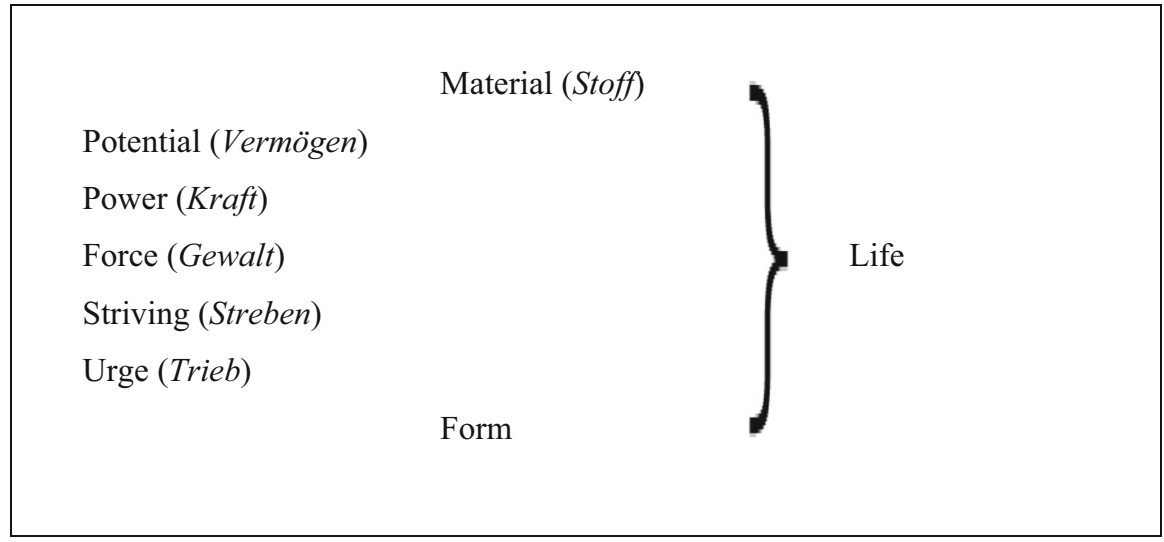

Fig. 1 Life

Life, finally, must change in order not to die (von Weizsäcker 1987). As it develops each stage must perish in order to make room for the next stage; as must the organism as a whole to make room for new life. Death is hence a part of life rather than its opposite. As Goethe states most beautifully in his poem 'Eins und Alles ${ }^{8}$ :

To take what's made and then re-make it,

To fight rigidity and break it,

Eternal living action quest.

What never was grows real and fuller,

As pure clean suns, as worlds with colour,

And in becoming never rest.

It all must move, make new creations,

First take form, then transformations;

For moments it just seems held fast.

In all things life's perpetuated,

And all must be annihilated

That existence strives to last.

The second impression, interrelatedness, makes living organisms, as Goethe (1998c: 21) puts it, outwardly multi-faceted and inwardly inexhaustible, so that research into them can never come up with a comprehensive description. The way to study the inner life of organisms is to take their external expressions as signs of their inner lives, as we may take somebody's behaviour as sign of his character:

To look at products of nature in themselves, without relation to utility or effectiveness, without relation to a first cause, just as a living whole that includes, by virtue of being alive, cause and effect; that we can approach and ask to give account, that we can trust to tell us about the nature of its being. The parable of a free human being that does not obey either father nor master

\footnotetext{
$\overline{8}$ Translation from http://www.postpoems.org/authors/facethetruth2b/poem/920813.
} 
nor need. We watch him act and do not really understand why he acts in this way. We approach him and ask him why. He would give us his innermost and his circumstances and we would understand that he acts from necessity. (Goethe, no date: 108, my translation)

This 'freedom' of living beings is, as I have argued above, partly a freedom from efficient (mechanistic) causality as, first, living beings are their own causes in a Leibnizian sense, and second, are subject to a multitude of causalities that I will discuss in more detail in the respective section below. The all-encompassing life force, the source and ultimate idea of life, is Nature. Again, we find the idea of Her as an overflowing and in her interrelatedness over-rich entity:

Natural system: a contradictory expression. Nature has no system; and she has - she is - life and development from an unknown centre toward an unknowable periphery. Thus observation of Nature is limitless... ${ }^{9}$ (Goethe 1998c: 35)

Simmel takes from Goethe the notion of life as a unity permeating the various stages of development as well as the idea of life and form as the primary ontological forces that create all beings from their dialectic interplay. In Simmel's philosophy, however, the pair is evaluated unevenly with form acting as a threat to life. Life is permanently in danger of being stifled by the rigidity and lifelessness of form, whereas the opposite move-life breaking forms-is conceived as a liberating move. While form is needed to bring forth culture and society, it also inevitably leads to tragedy (see below). Life, in contrast, is permanent creativity and novelty; the connotation of 'vitality' at its best. Simmel's conception of 'more-life' (MehrLeben) and 'more-than-life' (Mehr-als-Leben) show quite clearly that he tends to regard life as the more fundamental category. This is not the evaluation that Goethe would take. To him, the 'rule' acts as a positive constraint, a moment of reflection or even contemplation born of human self-determination. Like the Kantian moral law, the rule represents human freedom vis-à-vis a creativity that is born of divine nature but to a certain extent beyond human control and understanding. Both authors also agree on death as something inherent to life, although Simmel's account goes beyond this idea to explore reincarnation. He also links death to different degrees of individuation ${ }^{10}$ when he explains that some persons are more individualised than others and that those persons' deaths cause the loss of 'a greater quantum of the world' (Simmel 1918: 134). Goethe, while promoting the idea of the genius elsewhere, is more pragmatic about this particular aspect when he remarks: 'There is no greater consolation for mediocrity than that the genius is not immortal' (Goethe 1988, no. 48).

\footnotetext{
9 All quotations have been translated by Naydler (1996), unless stated otherwise.

${ }^{10}$ Individuation is, in the classic Aristotelean tradition, the result of the form combining itself with (unformed) matter. One may think of a clay mould that produces an individual brick in this manner. Simmel's discussion of individuation is thus a continuation of his argument about life and form.
} 


\subsection{Causality}

Goethe's opposition against Newtonian science is in part fuelled by the latter's insistence on mechanistic, i.e. material efficient, causality. While Goethe does not doubt that it exists and plays an important role in the non-organic world, he would hold that, first, living organisms underlie a different causality (Schad 1977), and that second, the world in its totality and its polarity of matter and spirit knows many forms of causality that are not easily separated from one another. He lists them as:

... chance, mechanic, physical, chemical, organic, psychological, ethical, religious, ingenious (genial). We have made a step that was well considered but always seems risky: to describe all phenomena in continuous succession as they develop out of each other, transform into each other. (Goethe 1840a: 71)

In the same vein, he also cautions against looking for 'nearby,' direct or immediate, efficient causes when studying an effect. The phenomenon in its complexity affords long and intricate chains of causality that are, more often than not, non-linear. As a consequence, it may often be more correct to speak of 'correlations' in a phenomenon and leave it at that instead of establishing linear cause-effect chains. Goethe's rejection of mechanistic explanations for organisms is based on his conviction that they follow an inner 'programme' (see above) that functions as the main determinant of their development. We might call it entelechy were it not for the fact that, as Brady (1984) points out, Goethe does not regard the telos to mark the aim reached at the end of the developmental process (like the aim of an action) but as comprising it in its entirety. While organisms, as physical bodies, may be subject to efficient causality, the more important cause for their changes is this inner drive. As a consequence, two aspects move to the fore. The first is the relationship between the part and the whole that leads to an explanation of each part in terms of its function for, and place in, the whole. This function can be physical as well as spiritual but in any case the part contributes to something beyond itself. The second aspect relates to the relationship between the inner drive and the developmental process. As indicated above, the cause is not as clearly separable from the change as is the case with efficient and final causes. Organisms are inseparable from their potency for change (Brady 1984); in that sense, they are their becoming. ${ }^{11}$

In reality, any attempt to express the inner nature of a thing is fruitless. What we perceive are effects, and a complete record of these effects ought to encompass this inner nature. We labour in vain to describe a person's character, but when we draw together their actions, their deeds, a picture of their character will emerge. (Goethe 1998c: 315)

Simmel follows Goethe in his rejection of efficient causality. Instead of assuming a multiplicity of causal relationships or simple correlations, Simmel (1918: 99ff.), however, declares cause and effect to be (Kantian) subjective principles and reverts to an Aristotelian scheme that takes form and matter (continuity) to be the primal

11 This is a famous dictum of the process philosopher Whitehead (1985). 
ontological principles out of whose interplay everything emerges. This moves the focus from cause and effect to the transition from potentiality to actuality and hence to the process of becoming. ${ }^{12}$ Although this is very close to Goethe's thoughts, Simmel distinguishes between non-organic entities whose form is determined by external forces, and organic entities whose form is a self-sufficient entelechy. Both entities arise out of a formation process that, according to him, cannot be described exactly but results in individuation. This process of individuation is different even within the same species so that, for example, human beings differ with regard to their individuality. Husserl, in contrast, extensively develops how efficient causality rose to universal dominance with the mathematisation of physics, but does not say much in detail about other forms of causality.

\subsection{Phenomenon}

Goethe's way of doing science has often been labelled phenomenological (e.g. Heinemann 1934; Robbins 2006). His conception of the phenomenon and our access to it, however, differs from the way Husserl would conceptualize it. Before I move on to describe Goethe's conception of the phenomenon it is necessary to point out that this conception has changed over the course of his scientific writings. In 1794, recounting a meeting with Schiller, Goethe writes:

I gave a spirited explanation of my theory of the metamorphosis of plants with graphic pen sketches of a symbolic plant. He listened and looked with great interest, with unerring comprehension, but when I had ended, he shook his head, saying, "That is not an empiric experience, it is an idea." I was taken aback and somewhat irritated, for the disparity in our viewpoints were here sharply delineated. [...] Controlling myself, I replied, "How splendid that I have ideas with out knowing it, and can see them before my very eyes". (Goethe 1998a: 541f.)

The quote indicates a rejection of Kantian epistemology with its division between subject and object. More than thirty years later, however, Goethe recognises the difficulty of accessing the phenomenon immediately. He muses:

At this point we encounter a characteristic difficulty [...] namely, that a definite chasm appears to be fixed between idea and experience. Our efforts to overbridge the chasm are forever in vain, but nevertheless we strive eternally to overcome this hiatus with reason, intellect, imagination, faith, emotion, illusion, or - if we are capable of nothing better - with folly. By honest persistent effort we finally discover that the philosopher might probably be right to assert that no idea can completely coincide with experience, nevertheless admitting that the idea and the experience are analogous, indeed must be so. (Goethe 1998c: 31f.)

\footnotetext{
12 The interplay of potentiality and actuality is a central theme in the philosophy of becoming, see for example, Whitehead (1985).
} 
The hiatus between idea and experience is, however, not of a categorical nature but due to the limits of the human mind, as Goethe explains continuing:

...in an idea, the simultaneous and successive are intimately bound up together, whereas in an experience they are always separated. Out attempt to imagine an operation of nature as both simultaneous and successive, as we must in an idea, seems to drive us to the verge of insanity.

Even in this later stage, however, he would disagree with Husserl's focus on the world as immanent in consciousness and hold that the human observer of nature is directly involved with the phenomena both on a pragmatic and on a spiritual plane. First, human beings are part of nature and thus not categorically different from other natural objects. They are, by nature, linked to natural objects and it is in their nature-a necessity for survival - to perceive, understand and manipulate these objects. If they did not grasp the objects truly, they would not be able to apply them. Second, nature creates and operates in a way analogous to a creative human spirit. Therefore, ideas exist in nature, not just in the human mind. The true nature of an object is thus spiritual, and as such the human spirit can grasp it and, ideally, reconstruct the act of its creation. Through this reconstruction the human spirit participates in the object. To Goethe, phenomena are the ultimate building blocks of reality; there is nothing outside of them and nothing beyond them that would be inaccessible to the human mind:

The ultimate goal would be: to grasp that everything in the realm of fact is already theory. The blue of the sky shows us the basic law of chromatics. Let us not seek for something behind the phenomena - they themselves are the theory. (Goethe 1998b, no. 488)

In some respects Goethe's phenomena are like Leibnizian monads: As unifying principles of the various relations with their environment they form microcosms reflecting the macrocosm of nature. They also follow an internal programme in their development (their morphogenesis). Their qualities and relations are necessary. Goethe assumes that phenomena have an essence that defines them-he calls this 'form' or 'idea'-but, again like Leibniz, holds that this essence is of a changing nature. Its purest reincarnation is the primal phenomenon (Urphänomen). ${ }^{13}$ The primal phenomenon becomes visible through long and patient study that proceeds from the empirical phenomenon through the scientific phenomenon to the primal phenomenon (Goethe 1998c: 23ff.). While the scientific phenomenon is described by laying out different conditions and relations in a successive manner, the primal phenomenon appears (often only for a brief moment) as the synthesis and simultaneous picture of them all. As part of the Heraclitean Flow, phenomena are related amongst each other. Goethe uses different concepts to describe the various essences forming complexities of an ever increasing order (Kronenberg 1924): form is the essence of the individual organism, type that of the species, law denotes a connection of types and, finally, nature a connection of laws and the ultimate whole.

\footnotetext{
13 Goethe also refers to it as 'pure phenomenon' (reines Phänomen). I will, however, reserve this term for the Husserlian notion.
} 
All these essences stand in an organismic relationship to one another, i.e. each part is generative of the others and all contribute functionally to the whole.

For Husserl (1986), the phenomenon forms the cornerstone of his philosophy because he considers it to be the absolute given. Following Descartes' cogito ergo sum, he argues that while we cannot infer real existence of an 'I' (Descartes' sum) from the act of thinking we can nevertheless be certain of the fact that a thinking process (cogitatio) is happening and that this thinking process has a content (cogitatum). This, Husserl reasons, must then form the ultimate, undoubtable foundation of all further investigations into the possibility of knowledge and knowing (Erkenntnis). Although the phenomenon is immediately given to a thinking person, it is normally accompanied by a host of assumptions and inferences that are far less certain than the phenomenon itself. The 'normally' in the previous sentence refers to the attitude in which we live and experiences our everyday life, the 'natural attitude' (natürliche Einstellung) as Husserl calls it. The natural attitude is characterized by the absence of doubts about the possibility of knowing something with certainty. In the natural attitude people take the world for granted; they do not question its existence. They do not distinguish between different degrees of epistemic certainty and reserve hence no special place for the pure phenomenon as the absolute given. It is only when we apply Phenomenological Reduction and leave the natural attitude that we can isolate the pure phenomenon from other, less certain assumptions and inferences, most notably the assumption that a perceived object exists outside of our consciousness as a real-world object. Reduction proceeds in two steps. ${ }^{14}$ The first, which Husserl calls 'Eidetic Reduction' aims to separate the contingent from the essential qualities of an object in consciousness. By varying the attributes in a thought experiment (Eidetic Variation) the observer can determine which attributes are contingent to an object and can abstract from them, thus arriving at the object's invariant essence (Holzhey and Röd 2004: 148ff.; Husserl 1968). The second step, the Epistemological or Transcendental or Phenomenological Reduction, in contrast, requires the observer to leave the natural attitude by suspending the belief in the reality of the object. Husserl (1962: §40) refers to this suspension as 'bracketing' or epoché. From then on, real is what presents itself as real in consciousness. The epoché is important in order to be able to study the conditions of reality-making in which the transcendental Ego posits the world as given, objective, scientific and so on-the truly phenomenological task, if phenomenology is defined as the study of the essence of pure epistemological phenomena (Wesenslehre der reinen Erkenntnisphänomene) (Husserl 1986: 47). The transcendental Ego must not be mistaken for a psychological, individual Ego, as Husserl never ceases to emphasise. Studying the latter - the realm of psychology — can only render subjective truths, whereas studying the former-phenomenology_means studying a universal, and in this sense objective, constellation. The pure phenomenon is the essence (Wesen) of a subjective mental experience as derived from both reductions (Husserl 1986: 44).

\footnotetext{
${ }^{14}$ I follow Ströker (1983) in her distinction between Eidetic Reduction as a reduction from fact to essence and Phenomenological Reduction as a reduction from a being to its pure phenomenon. As Ströker makes clear, Husserl himself has not always followed this distinction consistently.
} 
We can thus see that Goethe and Husserl share a number of thoughts on the phenomenon. Both see it as an inexhaustible, complex part of the ever-changing ontological flow. Both would also argue that it is accessible to human study if a particular method is applied. In comparison, however, Goethe stresses the diachronic nature of the phenomenon undergoing continuous change. He seeks to capture this variety - be it the variety across phenomena or the variety of the same phenomenon over time - through careful observation and an ensuing synthesis in the mind. Husserl's method, in contrast, is one of privation aiming to arrive at the invariant essence by abstracting from the multitude of appearances. Goethe is also quite happy to make ontological assumptions regarding the interrelatedness of phenomena or their cosmological function. The major reason for this is Goethe's strong emphasis on the pragmatic function of knowledge, i.e. the idea that any knowledge must serve a purpose. This purpose is not as narrowly defined as utility or technical applicability but may also be connected to contributing to living everyday life in moral terms. The 'deed' (Tat) is Goethe's highest category in which human perfection can become visible. Due to this commitment, Goethe's primal phenomenon is easier to conceptualize as the ultimate building block of his natural philosophy. While Husserl remains focused on consciousness and refers only vaguely (mostly by bracketing) to the physical world, Goethe can collapse both and argue that what we ultimately 'see' as primal phenomena is indeed in an ontological sense the essence of the natural world. Husserl (1962: 116, translation by Simms and myself) himself addresses this distinction in a passage in which he probably refers to Goethe's primal phenomenon of the plant:

All objective consideration of the world is consideration of the "exterior" and grasps only "externals", objective entities. The radical contemplation of the world is a systematic and pure internal consideration of the subjectivity which "externalizes" itself in the exterior. It is like the unity of a living organism which you can consider and dissect from the outside, but which you can understand only if you go back to its hidden roots and systematically follow the formative life force in all its achievements as it arises in the roots and strives upwards from them. Is this, however, only a simile, and is not, in the end, our human being and its consciousness with its deepest world problematization the locus where all problems of inner being and external representation are addressed?

At the end of the day, the primal/pure phenomenon of the plant cannot be more that a simile for Husserl, a simile depicting the invariant structures of existence as they appear in consciousness (Simms 2005), while for Goethe it remains a truly existing, underived entity.

Simmel straddles both positions. He agrees with Goethe on the objective entity of the organism as represented by its entelechy. With regard to non-organic entities like actions or things, however, he follows the idealist tradition in saying that it is the mind that constitutes their entity. 


\section{The relationship between observer (subject) and observed (object)}

From what I have said about Goethe's conception of phenomena, primal phenomena and the observers' access to them, it should be clear that the subject-object problem is not a pressing one because the Kantian distinctions between noumena and phenomena, between nature and culture, are, to Goethe, not categorical distinctions. He, furthermore, assumes that an object's qualities emerge in the relation between observer and observed in a unique moment of experience. They are in this sense neither subjective nor objective but relational. This relationality has an ontological quality as being known changes the phenomenon. ${ }^{15}$ Perception is in this sense creative (Stephenson 1995). It is also ecstatic in the literal sense of the word as reaching out beyond the observer. This also means that the observer is a true participant in the process who emerges as changed from it as does the observed. In this process of co-creation, the wish to manipulate and control nature gives way to a 'Delicate Empirics' (Zarte Empirie) that retains wonder and admiration in its studies of the phenomena. It also implies what Whitehead (1993) calls-non-disparagingly - a 'Provisional Realism' in which nothing is hidden from the observer's perception. There are no primary qualities hidden behind, or even beyond, the phenomenon. On the contrary, phenomena display relations, tensions and intensities that belong to their nature and can be felt by the observer just as the observer can see, hear or smell their other qualities.

There is also an ecstatic aspect in Husserl's description of the relation between observer and observed. Although Husserl often discusses consciousness as something 'containing' cogitata, he does not entertain a homo clausus view (Prechtl 1998). On the contrary, consciousness has to 'reach out' into the world because it constitutes the very objects of this world. The world is the world we are conscious of, and consciousness, vice versa, needs the world to be conscious of something. In this sense, Husserl overcomes the Cartesian dichotomy of subject and object. Moreover, consciousness is first of all an act or an experience (Erlebnis) before it becomes a person's experience. The constitution of the subject follows the experience as an 'It is me who experiences this.' In this sense the psychological subject has the same status as a physical object in that both are constituted after, and out of, the initial experiencing act. They transcend it. It is only within this conceptual dichotomy of transcendence and immanence that Husserl talks of inside/ outside stressing that this is by no means a spatial distinction of 'inside/outside someone's head.' This implies that there is an important epistemological distinction between cogitatio-cogitatum on the one and psychological subject-physical object on the other hand. Phenomenology only really concerns itself with the first two because they are undoubtedly given and constitute the pure phenomenon. The latter pair corresponds to the former but forms the concern of the natural attitude because it transcends the phenomenon. It is hence not undoubtedly given but subject to ontological assumptions that are part of the natural attitude.

15 Bortoft (1986: 70) relates this thought back to Aristotle's treatise 'On the Soul' (214). Aristotle explains that the soul as the entelechy of the living organism is a form (or idea), and as such will move from an ontological state of potentiality to a state of actuality as it is grasped by an intellect. 
Both authors thus describe subject and object as constituted in analogous processes: for Husserl the constituting entity is consciousness, whereas for Goethe it is nature. The difference between them is marked by Kant. For Husserl, the critical Cartesian who takes the 'cogito' as his starting point, the dichotomy between res extensa and res cogitans remains in place as the pure phenomena shown within consciousness are not the physical phenomena found in nature. Husserl (1950: §90) speaks of the physical entity as a 'correlate' to its conscious perception (cogitatum). As we perceive everything as something, the cogitatum consists of two layers (Schichten): a sensual or hyletic layer and an intentional, sensemaking or noetic layer. ${ }^{16}$ It is only the act of perception, and more precisely the noetic aspect of that, that creates objects from the Heracliteian, chaotic flow of phenomena. Similar to Kant, Husserl therefore holds that the reality of things (as meaningful things) is in their cogitata, but that we must not infer from that that the things in nature are just appearances (Holzhey and Röd 2004: 149). The Heracliteian flow exists but we cannot say anything about it that is not something related to a cogitatum.

For Goethe, the contemporary of Kant who kept his distance from the genius of Königsberg, everything is infused with spirit (Geist) and matter. Together they form the basic polarity that drives nature. He can hence say that, first, both the observer and the observed are created by nature, but also secondly and more importantly that the human mind can emulate nature in its creative process and create objects of its own for nature operates with ideas just as the human mind does. Goethe hence follows Spinoza rather than Descartes in his ontology of mind and matter.

The second major point of divergence is the status of the individual experience of the observer. While both object to the universalisation won through inductive abstraction, their concept of the relationship of particular and universal differs markedly. For Husserl the individual experience is initially subjective and private but can be universalised in Transcendental Reduction. For Goethe, the individual experience remains unique and unrepeatable because it is constituted by a set of relations between the observer and the observed in a particular time and place:

The manifestation of a phenomenon is not independent of the observer - it is caught up and entangled in his individuality' (Goethe 1988, no. 1224)

There is, however, universality in each case because each particular phenomenon is a microcosm reflecting the universal.

Since neither knowledge nor reflection can summon the whole - the former lacks the internal, the latter the external perspective - we must conceive science as an art if we expect any holistic results. We must not, however, seek those in the universal or exaggerated. On the contrary, like art always presents itself wholly in one piece of art, so science should present itself wholly in each single study. (Goethe 1998d: 41, my translation)

\footnotetext{
${ }^{16}$ For a more in-depth discussion of the nature of noema and their relation to meaning and sense see Føllesdal (1969).
} 


\section{Methods}

This is probably the part most explicitly and extensively covered in Goethe's works. His deep respect for the manifoldness of natural phenomena and his related suspicion of every attempt to understand them in a 'dead,' i.e. mechanistic or staticclassificatory, way drive him to adopt methods that are, on the one hand, alert to empirical variation and change but, on the other hand, also conscious of the need to find the form that, like his Bildungstrieb, guides the development of that variety. The first parts leads him to a relentless, almost obsessive, observation of the phenomenon referring each subsequent operation stubbornly back to the immediate experience of the object: 'The senses do not deceive, judgment does.' (Goethe 1988, no. 1193). This is particularly true for any form of abstraction, inference, hypothesis or theory building:

How difficult it is, though, to refrain from replacing the thing with its sign, to keep the object alive before us instead of killing it with a word. (Goethe 1998c: 492)

And:

All hypotheses get in the way of the anatheorismos - the urge to look again, to contemplate the objects, the phenomenon in question, from all angles. [...]. (Goethe 1988, no. 1221)

On the other hand, he just as readily concedes that experience is not limited to sense perception:

An extremely odd demand is often set forth but never met, even by those who make it: that is, that empirical data should be presented without any theoretical context, leaving the reader, the student, to his own devices in judging it. This demand seems odd because it is useless simply to look at something. Every act of looking turns into observation, every act of observation into reflection, every act of reflection into the making of associations; thus it is evident that we theorise everytime we look carefully at the world. The ability to do this with clarity of mind, with self-knowledge, in a free way, and (if I may venture to put it so) with irony, is a skill we will need in order to avoid the pitfalls of abstraction and obtain the results we desire, results which can find a living and practical application. (Goethe 1998c: 317)

Phenomena are inexhaustible, and observers must use all faculties to experience them, researchers every method available:

None of the human faculties should be excluded from scientific activity. The depth of intuition (Ahnung), a sure awareness (Anschauen) of the present, mathematical profundity, physical exactitude, the heights of reason (Vernunft), and sharpness of intellect (Verstand) together with the versatile and ardent imagination, and a loving delight in the world of the senses - they are all essential for a lively and productive apprehension of the moment. (Goethe 1998d: 41) 
'Anschauung' is of particular importance because it allows us to picture the development rather than just a static configuration. Again, the German expression is difficult to translate. Many render it as 'intuition' to capture its introspective, often fleeting and vague, aspects. The German word, however, derives from 'schauen', which means 'to see' both in its simple form of visual sense perception and its enhanced form of seeing the future or something transcendental. There is hence a practical, everyday component in it that 'intuition' does not capture. Goethe (1998c: 40) speaks of a 'pregnant aspect' (prägnanter Punkt) in which the observer sees, realizes or intuits the inner form of the phenomenon. Thus Goethe defines Morphology as:

... to understand living development as such, to see and grasp its exterior parts as they relate to each other, to understand them as signs of the interior and to master thus the whole in imagination (Anschauung) (Goethe 1998c: 55, my translation)

And:

I had the ability, with my eyes closed and my head lowered, to evoke the image of a flower in the centre of my organ of visualization; and to perceive the flower in such a way that it did not remain in its original form for a single moment, but spread out, and from within there unfolded again new flowers with colours as well as green leaves. They were not natural flowers by any means, but products of the imagination [...] It did not occur to me to experiment like this with other objects. Perhaps these offered themselves so readily because they had their roots in many years of contemplation of the metamorphosis of plants. (Goethe 1824)

Researchers will find themselves moving back and forth between the empirical experience and their inner vision looking for the idea of the phenomenon. ${ }^{17}$ The full scope of the phenomenon is reached by differentiating the various experiences of a phenomenon rather than looking for similarities in them. In contrast to modern quantitative science the aim is never to form abstractions inductively, but to let the differences stand as legitimate expressions of the complexity of the phenomenon. To reach a synthesis from this multitude of differences, however, then becomes a difficult endeavour. Goethe claims that it can, at best, only be there for a brief, fleeting moment of 'Anschauung.' This synthesis is much more of an aesthetic than a cognitive nature as rational-conceptual thinking plays a part but not the central role. The stress on difference rather than commonalities has earned Goethe's method the label of a 'science of qualities' (Amrine et al. 1987). While Newtonian science is based on the idea of the extensiveness and homogeneity of matterpermitting quantification and reduction-Goethean science studies intensities based on unique, different experiences. Rather than finding unity through the homogenization and reduction of multiplicity, it aims at finding the indivisible unity that encompasses the multiplicity of the phenomenon (Bortoft 1986). Most importantly

\footnotetext{
17 A detailed description of the stages of this 'back and forth' can be found in Robbins (2006) and Holdrege (2005).
} 
in this, researchers must avoid the temptation to form theories before they have grasped the full scope of the phenomenon.

Theories are often the hasty results of an impatient mind that want to rid itself of the phenomena and replace them with images, concepts or even just words.

(Goethe 1988, no. 428)

When talking about the spiritual aspect of Goethe's Empirics, a second component should not be overlooked. 'Anschauung' is not only important because the synthesis of experiences cannot be achieved anywhere but in the mind but also because it represents a creative act of thinking. This creative act reconstructs the original creative act of Nature. Nature, according to Goethe (1998c: 31), has ideas and brings forth the phenomena in an act very similar to an artist producing a work from an idea.

This is also, I would hold, the source of Goethe's definition of exactitude, as recreation requires a specific form of exactness that does justice to the individual while at the same time understanding the general principle. Exactitude, to him, refers not to the numerical distance of a taken measurement to the object's 'real' or commonly accepted quality. It does, however, refer to connotations like diligence, constancy and rigour. And Goethe adds the notion of adequacy as a link to the ever present human, spiritual dimension of learning when he says (Goethe 1998b, no. 664):

In so far as we make use of our healthy senses, the human being is the most powerful and exact scientific instrument possible. The greatest misfortune of modern physics is that it experiments have, as it were, been set apart from the human being; physics refuses to recognise in Nature anything not shown by artificial instruments, and even uses this as a measure of its accomplishments.

And:

People who look through glasses [that is, microscopes and telescopes] think themselves cleverer than they are: for their external sense is in this way taken out of equilibrium with their inner capacity for judgment. (Goethe 1998e: 120)

As such, exact sensorial imagination is not an oxymoron but the descriptor of a process in which the scientist reverts to the careful (multi-faculty) observation of the object until s/he is capable of re-creating every detail of it in their imagination.

The balance and development of human capacities are what makes Goethe's empirics 'delicate.' There is an interplay of nuances, an awareness that rejects the striking and immediate, a challenge and an invitation that results from listening to Nature. In contrast, Goethe compares the scientific methods of his time to a torture chamber (Goethe 1998b, no. 498) and warns:

If the scientist wants to defend his right to a free description and study, he should also feel obliged to secure the rights of Nature. Only where She is free, will he be free; where She is bound by human conventions, he will find himself bound too. (Goethe 1840b: 164) 
While Goethe would regard Delicate Empirics a general scientific method, Husserl considers phenomenology to be as much a method as a science. The core part of his method in this sense is to approach the pure phenomena by switching from the natural attitude to the phenomenological attitude. This is achieved through Phenomenological Reduction in which we exclude all transcendental assumptions (i.e. theories, assumptions, inductions, deductions) and reduce the phenomena we perceive to pure phenomena. As Husserl bans induction, deduction and other forms of logical inference in the Phenomenological Reduction the perception of pure phenomena is more alike to 'seeing' than to 'thinking' the phenomenon (Rombach 1994). Not surprisingly then, he uses the same term as Goethe: Anschauung. The idea of varying the characteristics of the object in a thought experiment (Husserl: eidetic variation, Goethe: exact sensorial imagination) also seems the same. Overall, however, Husserl would refrain from Goethe's wide use of epistemic faculties and limit himself to the cognitive spectre. Applying the methods, both seek objective knowledge although Husserl, post Kant, feels that he has to make a big effort to reach it, while Goethe is not impeded by a categorical distinction of subject and object. The aim of the thought experiment is, furthermore, a different one, as I have pointed out above: while Goethe aims at manifoldness, Husserl aims at reduction. Husserl would also agree with Goethe that the method needs to be exact (Goethe uses the word repeatedly in his description of the methodological stages, for example 'exact sense perception' or 'exact sensorial imagination') in order to render useful results. This is the only point where Simmel, who otherwise does not talk about methods for the study of life, would interfere to maintain that exactness is a characteristic of form and thus categorically opposed to life. The stream of life, as far as it is knowable at all, can only be grasped in an intuition as fluid and ephemeral as the stream itself.

\subsection{The relationship between culture and nature}

Goethe proposes analogous methods for the study of culture and nature as the two realms are not separated. Every phenomenon has material as well as spiritual aspects that must both be grasped in order to understand the phenomenon fully. The two even merge in the act of knowing or imagining as the mind (re-)creates the object with the help of the same ideas that nature uses in her original creative act (Kuhn 1987). Here Goethe inverts the Kantian dictum that all nature is culture because it is construed by human minds that cannot escape their cultural formation. For him, nature is culture too, but because nature, like human minds, works from ideas to create its subjects. Moreover, Goethe does not want to control and manipulate nature but advocates a Delicate Empirics that treats nature as a source of inspiration and admiration rather than something subjected to human fancy (Robbins 2006).

A second point relating nature and culture is that the aim of the sciences is not just to gather knowledge about objects but to contribute to an understanding of the world that is moral as well as epistemic. Scientists, like any other human being in Goethe's view, must strive for moral self-perfection, and hence their occupation 
must be such as to contribute to this aim (Amrine et al. 1987). This is the point where Goethe's critique of Newtonian mathematized science becomes harshest.

Both Husserl and Simmel agree with Goethe's second point. In fact, the 'distant rumble on the horizon' (Simms 2005: 161) disturbing Goethe in the eighteenth century had become a full-blown storm of discontent by the time Husserl and Simmel wrote. Husserl dedicates a whole book to the 'crisis of the European sciences' in which he describes how the sciences have become mere 'factual sciences' (Tatsachenwissenschaften) unable to treat 'problems of humankind' (Menschheitsfragen) concerning the ultimate sense or purpose of human being. Life philosophy as a movement, too, stands in almost programmatic rejection of modern science arguing that its gathering of abstract knowledge through exact methods misses the most fundamental and existential issues. [It is worth noting, however, that the school would raise the same concerns over Husserlian Phenomenology (Roesner 2012).] Simmel, however, takes a more subtle stance. He argues that, on the one hand, there is a certain 'normality' in the development of modern science as something set apart from everyday life. It is the result of a process occurring every now and again in which a section of the everyday world, rather than being subordinate and instrumental to the purposes of everyday life, develops a purpose in itself and starts to subordinate the everyday world to this purpose. It also develops forms that guide and constrain the previously free flow of life. Simmel calls this 'axis rotation' (Achsendrehung) and regards it the origin of culture. The implicit paradox - that life brings forth culture which then tries to stifle life- he refers to as 'tragedy of culture' (Tragödie der Geisteskultur). In this sense, then, science is no different from other cultural regimes like religion or the economy. The specifically modern problem, however, is the divergence between personal and objective culture (personaler und sachlicher Kultur) (Gerhardt 1971; Simmel 1907). As a result of the increasing division of labour, personal culture becomes disconnected from objective culture and does not develop at the same pace. It can thus draw less and less on objective culture for its self-realization and is more and more at risk to be completely subjected to objective culture. Simmel, in sum, conceptualizes the danger to human morality more broadly with science as one factor among several.

As to Goethe's first point, the pan-spiritual conception of nature, Simmel would probably agree where Husserl would not. For Husserl, human consciousness is a unique center of understanding in the world where Goethe would only concede that it is a higher form of understanding. Simmel's philosophy of life does not explicitly concern itself with nature although we might infer that he tends toward Goethe's view rather than toward Husserl's when he defines life as a form of existence that does not limit its reality to the present (Simmel 1918: 12). Continuity (flow) and form as the ultimate shaping principles, too, are borrowed from Goethe.

\section{Conclusion}

Goethe presents a natural philosophy and method that is original and strikes a careful balance between life philosophy and phenomenology. In comparison with Simmel, he is less vitalist, i.e. less enthusiastic about pure creativity and abundant 
production. For Goethe, the form-giving idea needs to be present as well and in the same measure. What Simmel considers to be rigid and stifling is for Goethe a necessary check on what would otherwise be 'brute' forces. It is, for all its evident problems, the lingering spirit of the Enlightenment coupled with the experience of the failures of the French Revolution that make Goethe demand a balance of order and force, of reason and emotion. In this he is also more optimistic than Simmel, who writes in the middle of large-scale industrialization and World War I. Goethe's phenomenology is directed towards the world ('Nature'), not just towards (human) consciousness within it. This world is not a correlate of experience whose validity is born out of that experience, but something in which human beings thrive or fail. It is a challenge, not in terms of gaining control over it but of developing the faculties to become worthy of it. As such, the sciences and humanities cannot be separate spheres developed in a process of societal differentiation but must always be measured by their contribution to help human beings gain wisdom and thus moral perfection. Life is wisdom, and wisdom is gained through the study of phenomena.

\section{Consequences for the study of life}

Students of life may not only feel inspired by Goethe's approach but also get pragmatic and detailed advice how to go on about it. A few fundamental issues emerge from the above discussion that are worth reiterating because each student will have to take a stance on them, whether implicitly or explicitly.

The conceptualization of life has, in Goethe as well as in others, been couched in terms of a dialectics between a creative, dynamic source and a fixed, recurring factor. Only recently, complexity theory (Goodwin 1997) has put forward that life develops in the space between rigid structure and absolute chaos. How these opposing forces interact needs to be spelled out as well; Goethe's solution for this is a dialectical one. The ontological status of the stable factor-called form or idea by Goethe and many others - needs to be addressed. Goethe's solution of a visible idea is unique (Bortoft 1986, with reference to Cassirer), but not the only available. It is remarkable, however, how many process thinkers (for example, Leibniz or Whitehead) go back before Kant and Descartes to avoid the subject-object dichotomy that adds an additional difficulty to this discussion. As soon as mind and matter are conceptualized without a categorical difference, a visible idea becomes a possibility.

At the same time, the chasm between observer and observed vanishes. This thought is rather appealing to modern sensitivities because it enables human observers to conceptualize nature as something in its own right rather than something to be manipulated. With regard to the social sciences, it seems an even more appropriate attitude towards the object of study. Holdrege (2005) discusses Goethe's Delicate Empirics in terms of a conversation with nature in the course of which both partners become enriched. Similar notions are treated under Shotter's (2005) 'withness-thinking' or Kaplan's (2005) 'reading a gesture' in the context of social inquiry. This also feeds into the moral aspect of science as discussed above. 
Defining the difference between mind and matter in degrees rather than categories also opens up the path for a discussion of intensification, which Goethe considered one of the most important trajectories in the development of life. This thought is echoed in the philosophy of Langer (1970), but also in the Nobel prize winner Sperry's (1980) treatise on life. A second issue here is whether intensification can adopt a causal role in the scheme of life. Goethe has made it quite clear that efficient causality alone will not take us very far, and that it may even be more useful to avoid causal explanations, especially those of a linear nature.

The 'science of qualities' that he has heralded certainly adopts a very complex picture of a heterogeneous multiplicity that we must aim to describe rather than reduce to explain - which is difficult enough. Developing a language for this in each discipline rises as a fascinating challenge. In contrast to Simmel and many contemporary process thinkers Goethe would maintain that this description should strive to be exact in order to do justice to the multiplicity of the phenomena. Exactness here is not to be confused with reduction or simplicity. To those falling into this trap, Goethe's own conceptual scheme seems inconsistent (for example, Heinemann 1934). It is not. We may well assume that the man who helped shape modern German had quite an acute feeling for the terms he was using. Polyvalence, however, is not inconsistence nor is it vagueness. It is an adequate and artful description for complex phenomena.

Open Access This article is distributed under the terms of the Creative Commons Attribution 4.0 International License (http://creativecommons.org/licenses/by/4.0/), which permits unrestricted use, distribution, and reproduction in any medium, provided you give appropriate credit to the original author(s) and the source, provide a link to the Creative Commons license, and indicate if changes were made.

\section{References}

Amrine, F., F. Zucker, and H. Wheeler. 1987. Goethe and the sciences: A reappraisal. Dordrecht: Reidel. Bleicher, J. 2007. From Kant to Goethe. Theory, Culture \& Society 24(6): 139-158.

Bortoft, H. 1986. Goethe's scientific consciousness, vol. 22. Tunbridge Wells: Institute for Cultural Research.

Brady, R.H. 1984. The causal dimension of Goethe's morphology. Journal of Social and Biological Structures 7(4): 325-344.

Chia, R., and I. King. 1998. The organizational structuring of novelty. Organization 5(4): 461-478.

Clegg, S., M. Kornberger, and C. Rhodes. 2005. Learning/becoming/organizing. Organization 12(2): $147-167$.

Cooper, R. 2007. Organs of process: Rethinking human organization. Organization Studies 28(10): 1547-1573.

Fellmann, F. 1996. Geschichte der Philosophie im 19. Jahrhundert. Reinbek: Rowohlt.

Føllesdal, D. 1969. Husserl's notion of noema. The Journal of Philosophy 66(20): 680-687.

Galison, P.L., G.J. Holton, and S.S.S. Schweber. 2008. Einstein for the 21st century: His legacy in science, art, and modern culture. Princeton: Princeton University Press.

Gerhardt, U. 1971. Immanenz und Widerspruch: Die philosophischen Grundlagen der Soziologie Georg Simmels und ihr Verhältnis zur Lebensphilosophie Wilhelm Diltheys. Zeitschrift für philosophische Forschung 25(2): 276-292.

Goethe, J.W.v. 1824. Das Sehen in subjektiver Hinsicht von Purkinje. http://anthrowiki.at/Bibliothek: Goethe/Naturwissenschaft/Das_Sehen_in_subjektiver_Hinsicht.

Goethe, J.W.v. 1840a. Nachträge zur Farbenlehre Goethe's sämmtliche Werke in vierzig Bänden, vol. 40, 5-107. Stuttgart: J.G. Cotta'scher Verlag. 
Goethe, J.W.v. 1840b. Recht und Pflicht Goethe's sämmtliche Werke in vierzig Bänden, vol. 39, 164f. Stuttgart: J.G. Cotta'scher Verlag.

Goethe, J.W.v. 1988. Maximen und Reflexionen. Leipzig: Insel Verlag.

Goethe, J.W.v. 1998a. Werke. Autobiographische Schriften II, vol. 10. München: Dtv.

Goethe, J.W.v. 1998b. Werke. Maximen und Reflexionen, vol. 12. München: Dtv.

Goethe, J.W.v. 1998c. Werke. Naturwissenschaftliche Schriften I, vol. 13. München: Dtv.

Goethe, J.W.v. 1998d. Werke. Naturwissenschaftliche Schriften II, vol. 14. München: Dtv.

Goethe, J.W.v. ed. 1998e. Wilhelm Meisters Wanderjahre. In Werke, vol. 8, 7-516. München: Dtv.

Goethe, J.W.v. no date. Naturwissenschaftliche Schriften I, vol. XVI. Leipzig: Insel Verlag.

Goodwin, B. 1997. How the leopard changed its spots: Evolution of complexity. London: Phoenix.

Heinemann, F. 1934. Goethe's phenomenological method. Philosophy 9(33): 67-81.

Hernes, T. 2008. Understanding organization as process. Theory for a tangled world. Abingdon: Routledge.

Holdrege, C. 2005. Doing Goethean science. Janus Head 8(1): 27-52.

Holzhey, H., and W. Röd. 2004. Geschichte der Philosophie. Die Philosophie des ausgehenden 19. und des 20. Jahrhunderts. Neukantianismus, Idealismus, Realismus, Phänomenologie, vol. XII/2. München: C.H. Beck.

Husserl, E. 1950. Ideen zu einer reinen Phänomenologie und Phänomenologischen Philosophie, vol. 1. Den Haag: Martinus Nijhoff.

Husserl, E. 1962. Die Krisis der Europäischen Wissenschaften und die Transzendentale Phänomenologie. Den Haag: Martinus Nijhoff.

Husserl, E. 1968. Phänomenologische Psychologie. Den Haag: Martinus Nijhoff.

Husserl, E. 1986. Die Idee der Phänomenologie. Hamburg: Felix Meiner.

Jensen, A.K. (Ed.). 2011. Internet Encyclopedia of Philosophy.

Kaplan, A. 2005. Emerging out of Goethe: Conversation as a form of social inquiry. Janus Head 8(1): 311-334.

Kronenberg, M. 1924. Goethes Naturanschauung. Die Naturwissenschaften 12(44): 911-915.

Kuhn, D. 1987. Goethe's relationship to the theories of development of his time. Goethe and the sciences: A reappraisal, 3-15. Dordrecht: Reidel.

Langer, S. 1970. Mind. An essay on human feeling. Baltimore: The Johns Hopkins Press.

Lash, S. 2005. Lebenssoziologie. Georg Simmel in the information age. Theory, Culture \& Society 22(3): $1-23$.

Lenoir, T. 1987. The eternal laws of form: Morphotypes and the conditions of existence in Goethe's biological thought. In Goethe and the sciences: A reappraisal, ed. F. Amrine, F. Zucker, and $\mathrm{H}$. Wheeler, 17-28. Dordrecht: Reidel.

Levine, D.N. 2012. Soziologie and Lebensanschauung: Two approaches to synthesizing 'Kant'and 'Goethe'in Simmel's Work. Theory, Culture \& Society 29(7-8): 26-52.

Naydler, J. 1996. Goethe on science. An anthology of Goethe's scientific writings. Edinburgh: Floris Books.

Prechtl, P. 1998. Edmund Husserl zur Einführung. Hamburg: Junius.

Richards, R. 2002. The romantic conception of life. Chicago: University of Chicago Press.

Robbins, B.D. 2006. The delicate empiricism of Goethe: Phenomenology as a rigorous science of nature. Indo-Pacific Journal of Phenomenology: Methodology: Special Edition 6: 1-13.

Roesner, M. 2012. Zwischen transzendentaler Genese und faktischer Existenz. Konfigurationen des Lebensbegriffs bei Natorp, Husserl und Heidegger. Husserl Studien 28: 61-80.

Rombach, H. 1994. Phänomenologie des sozialen Lebens. Freiburg: Alber.

Sandelands, L. 1995. The idea of social life. Philosophy of the Social Sciences 25(2): 147-179.

Schad, W. 1977. Man and mammals. Toward a biology of form. New York: Waldorf Press, Adelphi University.

Shotter, J. 2005. Goethe and the refiguring of intellectual inquiry: From 'aboutness'-thinking to 'withness'-thinking in everyday life. Janus Head 8(1): 132-158.

Simmel, G. 1907. Philosophie des Geldes. Leipzig: Duncker \& Humblot.

Simmel, G. 1918. Lebensanschauung. Leipzig: Duncker \& Humblot.

Simms, E.-M. 2005. Goethe, Husserl, and the crisis of the European sciences. Janus Head 8(1): 160-172. Sperry, R. 1980. Mind-brain interaction: Mentalism, yes; dualism, no. Neuroscience 5(2): 195-206.

Stephenson, R.H. 1995. Goethe's conception of knowledge and science. Edinburgh: Edinburgh University Press. 
Ströker, E. 1983. Phänomenologie und Psychologie. Die Frage ihrer Beziehung bei Husserl. Zeitschrift für philosophische. Forschung 37(1): 3-19.

Swedberg, R. 2011. Georg Simmel: The view of life: Four metaphysical chapters. Human Studies 34(2): 229-230.

von Weizsäcker, C.F. 1987. Goethe and modern science. Goethe and the sciences: A reappraisal, 115-132. Dordrecht: Reidel.

Whitehead, A.N. 1985. Process and reality. New York: Free Press.

Whitehead, A.N. 1993. Science and the modern world. In Great books of the Western world, vol. 55, ed. M. Adler, 135-234. Chicago: Encyclopedia Britannica. 